\title{
Comparação entre folhas sombreadas de sete clones adultos de seringueira
}

\author{
Elenice de Cássia Conforto ${ }^{1}$, Nelson Sabino Bittencourt Júnior ${ }^{2}$, Erivaldo José Scaloppi Junior ${ }^{3}$, Rogério Manoel \\ Biagi Moreno ${ }^{4}$
}

\section{RESUMO}

Nas seringueiras, o substrato para a síntese do látex provém, em curto prazo, do processo fotossintético, realizado em sua maioria por folhas dos estratos sujeitos à radiação sub-saturante. Neste estudo, foram avaliados e comparados (1) os teores de pigmentos fotossintéticos (clorofilas a, b e carotenóides totais); (2) a espessura foliolar total e dos parênquimas clorofilianos; e (3) a área e peso da matéria seca foliar de folhas sombreadas, para seis clones de seringueira selecionados pelo Instituto Agronômico de Campinas (IAC), comparativamente ao tradicional clone RRIM 600. Em média, os teores de clorofila total $(\mathrm{a}+\mathrm{b})$ e de carotenóides totais foram, respectivamente, de 3,14 e 1,04 mg g-1 de peso fresco, sempre superiores ou iguais ao da testemunha. A espessura foliolar média foi de 119,62 $\mu$ m e mostrou grande variação entre os clones IAC, e destes quanto à testemunha. A área foliar média, de 219,17 cm², foi quase equivalente para todos os clones. Aárea foliar específica foi, em média, de 198,08 $\mathrm{cm}^{2} \mathrm{~g}^{-1}$, e neste caso, o maior valor foi observado para o IAC 56, sendo os demais, inferiores ou equivalentes ao da testemunha. Os clones IAC 302 e IAC 303 mostraram-se estatisticamente similares ao RRIM 600 para todos os caracteres analisados, e uma relação com a produtividade foi sugerida para o clone IAC 303.

Palavras chave: Hevea brasiliensis, pigmentos fotossintéticos, anatomia foliar.

\section{ABSTRACT}

\section{Comparisons among shade leaves of seven adult rubber tree plants}

In rubber trees the raw material for latex synthesis becomes, in short term, from the photosynthetic process performed mostly by leaves under sub-saturate radiation. In this study were evaluated and compared the following parameters in six clones selected by Instituto Agronômico de Campinas (IAC) with one another and with the traditional RRIM 600 (control): (1) photosynthetic pigment concentrations (chlorophyll a, b and total carotenoids); (2) total leaflet, palisade and spongy chlorenchyma thickness; and (3) area and dry mass weight of shade leaves. The mean

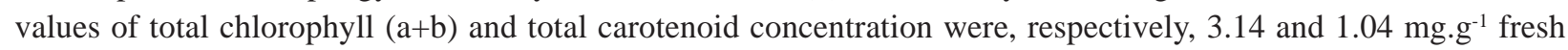
weight, always superior or equal to the control. The mean leaflet thickness was $119.62 \mu \mathrm{m}$ and varied between clones and control. The mean leaf area was $219.17 \mathrm{~cm}^{2}$ and nearly equivalent for all clones. The specific mean leaf area was $198.08 \mathrm{~cm}^{2} \mathrm{~g}^{-1}$, and IAC 56 showed the greater value, with values from other clones inferior or equal to the control. For all the characters analyzed, the clones IAC 302 and IAC 303 were statistically similar to RRIM 600 and a relationship with productivity was suggested for IAC 303.

Key words: Hevea brasiliensis, photosynthetic pigments, leaf anatomy.

Recebido para publicação em junho de 2009 e aprovado em setembro de 2010

${ }^{1}$ Bióloga, Doutora. Departamento de Zoologia e Botânica, Universidade Estadual Paulista Julio de Mesquita Filho. Instituto de Biociências, Letras e Ciências Exatas. Rua Cristóvão Colombo, nº 2265, 15054-000. São José do Rio Preto, SP, Brasil. elenice@ibilce.unesp.br.

${ }^{2}$ Biólogo, Doutor. Departamento de Zoologia e Botânica, Universidade Estadual Paulista Julio de Mesquita Filho. Instituto de Biociências, Letras e Ciências Exatas. Rua Cristóvão Colombo, $n^{\circ} 2265,15054-000$. São José do Rio Preto, SP, Brasil.

${ }^{3}$ Agronômo, Doutor. APTA - Polo Regional do Noroeste Paulista. Rodovia Péricles Bellini, Km 04. Votuporanga, 15500-970, Votuporanga, SP. Brasil.

${ }^{4}$ Químico, Doutor. Embrapa Instrumentação Agropecuária. Cx. Postal 741, 13560-970, São Carlos, SP, Brasil. 


\section{INTRODUÇÃO}

O consumo mundial de borracha (natural e sintética) vem aumentando, e o consumo do Brasil vem aumentando de forma ainda mais rápida; para 2020, admite-se que a produção possa atingir 250 mil toneladas frente a um consumo potencial de 500 mil toneladas, segundo estimativas do International Rubber Study Group (Gameiro \& Perozzi, 2008). Este cenário somente será modificado com sérias interferências na cadeia produtiva, atentando para o suprimento da demanda sem contar apenas com a expansão da área cultivada, mas também pela introdução de clones com menor período de imaturidade e maior produção.

Além disso, estudos são necessários para o melhor entendimento da interação entre os fatores de desenvolvimento que determinam a produtividade, os quais envolvem atributos genéticos, ecológicos e fisiológicos. O sucesso na aclimatação de uma espécie está relacionado com a eficácia e rapidez com que os padrões de alocação de biomassa e comportamento fisiológico são ajustados em face das condições ambientais. Um dos aspectos decisivos nesta plasticidade adaptativa depende do ajuste do aparelho fotossintético, de modo a garantir maior eficiência de uso dos recursos do meio, começando pela conversão da energia radiante em energia química.

O papel primário da folha é capturar luz e $\mathrm{CO}_{2}$ para realização da fotossíntese que, nas seringueiras, é o substrato imediato para a síntese de látex. Embora as plantas C3 partilhem de um mecanismo fotossintético idêntico, há uma considerável diversidade de estruturas foliares que existem para atingir esta mesma finalidade. $\mathrm{O}$ arranjo e a morfologia foliar variam grandemente entre as espécies, e às vezes até dentro da mesma espécie, havendo substancial variação tanto em escala macro quanto microscópica (Press, 1999). Deste modo, o significado funcional da estrutura foliar é dependente do ambiente que se encontra, e a equivalência funcional indica que frequentemente há mais de uma solução para o mesmo problema.

Durante a ontogenia foliar ocorrem mudanças no comportamento fotossintético dos clones de seringueira; estudos realizados por Miguel et al. (2007) relatam que os níveis de pigmentos fotossintéticos são bastante reduzidos até o $32^{\circ}$. dia de idade foliar, havendo um aumento a partir do $37^{\circ}$. dia, e deste modo, aos 57 dias as folhas atingem o seu máximo desempenho fotossintético. Embora tenham seguido o mesmo padrão, os clones do estudo apresentaram taxas fotossintéticas significativamente diferentes.

Num seringal, as camadas superiores de uma plantação madura, com índice de área foliar acima de seis, interceptam até $75 \%$ da radiação fotossinteticamente ativa incidente, enquanto que uma significativa porção do total da área foliar presente nas camadas inferiores da copa está exposta a uma radiação sub-saturante (Nataraja \& Jacob, 1999). As diferenças anatômicas e fisiológicas entre folhas de sol e de sombra têm sido estudadas extensivamente, e algumas generalizações são possíveis. Folhas de sol geralmente são mais grossas (Lima Junior et al., 2005); têm maior superfície de mesofilo por unidade de área foliar (Nakazono et al., 2001); os cloroplastos apresentam menos membranas de tilacóide (Terashima et al., 2006). Em termos funcionais, apresentam maior taxa fotossintética por unidade de área foliar (Senevirathna et al., 2003); maior proporção entre clorofila a/clorofila b (Engel \& Poggiani, 1991; Nakazono et al., 2001); maior quantidade de Rubisco e fotossistemas mais complexos (Terashima et al., 2006). Para seringueiras, embora vários estudos enfoquem atributos da folha (Medri,1977; Gomez \& Hamzah, 1980; Medri, 1980; Medri \& Lleras, 1981, 1983; Lemos Filho et al., 1993; Martins \& Zieri, 2003; Miguel et al., 2007, dentre outros), nem sempre o foco são as folhas sombreadas, como os de Martins \& Zieri (2003) ou as diferenças entre folhas de sol e de sombra, conforme estudos de Senevirathna et al., 2003.

Dados de produção divulgados por Gonçalves et al. (2006) mostraram diferenças entre a produtividade de clones de seringueira da série IAC, que foram selecionadas pelo Instituto Agronômico de Campinas, com relação ao clone RRIM 600, de origem asiática e que é o tradicionalmente cultivado nesta região. Devido à preponderância do número de folhas de sombra sobre o número de folhas de sol, indicando o papel fundamental das folhas sombreadas para o balanço de carbono da seringueira, o principal objetivo deste estudo foi realizar uma avaliação das folhas sombreadas de seis clones adultos selecionados pelo Instituto Agronômico de Campinas (IAC) comparativamente às folhas de um clone tradicionalmente cultivado (RRIM 600) quanto ao teor de pigmentos fotossintéticos e características anatômicas. Adicionalmente, foi examinada a possível extensão da relação entre estas variáveis e a produtividade destes clones, utilizando os dados de produção média ao longo de seis anos de sangria, disponíveis em Gonçalves et al. (2006).

\section{MATERIAL E MÉTODOS}

O material empregado neste estudo faz parte de um experimento de avaliação com 72 clones para pequena escala, implantado em 1989 na Agência Paulista de Tecnologia dos Agronegócios (APTA) - Pólo Regional do Noroeste Paulista, estabelecido no município de Votuporanga (SP), a $20^{\circ} 20^{\prime} \mathrm{S}$ de latitude e $49^{\circ} 50^{\prime} \mathrm{W}$ de longitude, altitude de 510 $\mathrm{m}$. O solo do local é do tipo Argissolo Vermelho eutrófico, A moderado, textura arenosa/média. As plantas estão dispostas em blocos numa área total de 3,1 ha, distribuídas em parcelas contendo 12 plantas úteis cada, espaçadas em 3,0 m na linha e 7,0 m entre as linhas. Na ocasião da coleta (fevereiro de 2007), as plantas apresentavam a copa inici- 
ando-se entre 6 e 8 metros acima do solo. Foram utilizados seis clones IAC (40; 56; 300; 301; 302 e 303) e como testemunha, o clone RRIM 600, sendo que IAC 40 e RRIM 600 são representados por duas parcelas e os demais clones, por três; em cada parcela, de modo aleatório, foram escolhidas três e duas plantas, respectivamente, totalizando seis plantas amostradas por clone.

De cada planta foi coletado um ramo, o qual foi acondicionado em saco preto, e mantido sob condições climatizadas até o seu processamento no Laboratório de Fisiologia Vegetal da UNESP, São José do Rio Preto. As folhas foram mantidas intactas até o momento de sua utilização, sendo empregadas somente aquelas completamente expandidas e em bom estado fitossanitário.

Folíolos laterais foram utilizados para a determinação dos pigmentos fotossintéticos, conforme Hiscox \& Israelstam (1979). Os extratos foram obtidos com uso de dimetilsulfóxido (DMSO) após $2 \mathrm{~h}$ de incubação a $65^{\circ} \mathrm{C}$ e analisados em espectrofotômetro de absorção na região da luz visível nos comprimentos de onda de 480, 645 e 663 nm para determinação dos teores de carotenóides totais e clorofilas, com uso das fórmulas clássicas de Arnon (1949) e Hendry \& Price (1993). Foram realizadas 12 repetições para cada clone (duas por planta).

Para o estudo das características de espessura foliolar total (excluindo as cutículas), do parênquima paliçádico total (superior mais inferior) e do parênquima lacunoso, das folhas empregadas anteriormente foram retiradas seções na porção mediana do folíolo mediano, medindo $1 \mathrm{~cm}$ de largura por $0,5 \mathrm{~cm}$ de comprimento. As peças foram fixadas em $\mathrm{FAA}_{50}$ (formaldeído 4\%, ácido acético glacial e etanol 50\%, nas proporções de 5:5:90), infiltradas em parafina utilizando-se série butílica (Johansen, 1940) e seccionadas transversalmente em micrótomo rotatório Leica RM 2255, na espessura de 15 ìm. As secções foram coradas com Azul-de-Astra e Fucsina-Básica (Roeser,1972) para montagem de lâminas permanentes utilizando-se resina sintética Permount. As análises das secções foram realizadas com uso do microscópio Jenaval com câmara clara.

A área foliar (AF) foi determinada para folhas completas (Lim \& Narayanan, 1972), sendo mensuradas três folhas por planta. Em seguida, estas foram colocadas em estufa para secagem e posterior pesagem para se obter o peso da massa seca foliar (PMS) e calculo da área foliar específica (AFE=AF/PMS).

Para análise estatística dos dados considerou-se o delineamento experimental inteiramente ao acaso realizando-se análise de variância e teste F, ao nível de 5\% de significância e, em seguida, o teste de Tukey para comparação entre médias (UFSCar, 2008) com 5\% de probabilidade de erro, segundo Zar (1999). Antes das análises, os teores de pigmentos fotossintéticos foram convertidos em $\sqrt{ } \mathrm{x}$, sendo apresentados nas tabelas em seus valores originais.

\section{RESULTADOS E DISCUSSÃO}

Os teores médios dos pigmentos fotossintéticos são indicados na Tabela 1. Com exceção da relação entre Clorofilas Totais/Carotenóides Totais, os valores para os clones IAC foram iguais ou superiores aos da testemunha RRIM 600. Algumas tendências são verificadas no grupo dos resultados: maiores teores de clorofila $a$ (chla), clorofila $b$ (chlb) e clorofila total (chla+b) para IAC 56; maior teor de carotenóides totais para IAC 56 e IAC 301; maior relação chrla/chlb para RRIM 600 e menor para IAC 56; maior valor chltotal/carotenóides totais para IAC 56 e menor para IAC 300.

Os cloroplastos são as unidades fundamentais da fotossíntese; tipicamente, há cerca de 10 milhões de cloroplastos em cada $\mathrm{cm}^{2}$ de área foliar (Evans, 1999). A composição dos cloroplastos é flexível, sendo particularmente responsiva à luz ambiente, que altera a abundância relativa de muitos dos complexos protéicos, cujos componentes são regulados geneticamente, e a organização do aparato fotossintético das folhas de sombra reflete a sua adaptação para a coleta de luz de modo mais eficiente. Isto é representado pelo investimento maior em clorofilas $b$ e carotenóides (Hendry \& Price, 1993; Yano \& Terashima, 2001; Lichtenhaler et al., 2007), ou seja, no complexo antena, maximizando a absorção de luz.

No fotossistema II, presente em maior proporção em folhas de sombra, há maior proporção de clorofila $b$ do que clorofila $a$ (Nakazono et al., 2001); adicionalmente, a degradação da clorofila $b$ é mais lenta do que a da clorofila $a$ (Engel \& Poggiani, 1991).

O efeito global destes teores deve ser encarado com cuidado, uma vez que os estudos de Senevirathna et al. (2003) mostraram que somente níveis de sombreamento acima de $50 \%$ causam alterações significativas no teor das clorofilas, e as folhas dos estratos superiores aos estudados podem apresentar variações importantes no conteúdo devido à diferenças na arquitetura das copas. Desta forma, comparando as folhas dos estratos mais inferiores da copa, a maior acumulação destes pigmentos é um indício de maior capacidade de aclimatação, indicando igual ou superior capacidade para os clones IAC com relação à testemunha RRIM 600. Dentre os clones IAC, há indícios para supor um melhor desempenho para IAC 56.

As modificações nas estratégias fotossintéticas das plantas, contudo, não estão associadas, necessariamente, somente a maiores ou menores concentrações de clorofila, mas podem ser alteradas pela reorganização espacial dos cloroplastos na célula ou tecidos (Oguchi et al., 2003). Deste modo, os dados relativos à anatomia foliar podem fornecer mais indicativos sobre o desempenho das plantas. Na Tabela 2 são apresentados os resultados destes estudos, que mostraram diferenças significativas em todos os parâmetros avaliados. 
Com relação à espessura foliar total, o valor médio observado foi de 119,62 ìm, estando IAC 300 entre os mais espessos e IAC 40 entre os menos espessos. Foi observada a presença de uma dupla camada de células de parênquima paliçádico: uma superior, com células mais alongadas de altura média de 46,69 ìm, e uma inferior, com células mais baixas de altura média de 15,97 ìm. O parêquima paliçádico total mostrou uma tendência de maior espessura para IAC 301 e 303. Com relação ao parênquima lacunoso, o valor médio observado foi de 35,99 ìm, com tendência de maior valor para IAC 300 e menor valor para IAC 40. A relação entre parênquima paliçádico e parênquima lacunoso tendeu a ser maior para IAC 40 e menor para IAC 300.

A presença de duas camadas de parênquima paliçádico, uma superior com células mais alongadas, e uma inferior com células mais baixas, é característica marcante de folhas de seringueira coletadas a partir de 4 metros de altura (Medri, 1977).

Além da altura de coleta, outros fatores atuam na determinação da espessura foliar, tais como a ploidia (Medri \& Lleras, 1981); variação clonal (Gomez \& Hamzah, 1980); local e condições de cultivo (Conforto, 1995; Martins \& Zieri, 2003). Desta forma, é mais adequado realizar a com- paração dos valores entre folhas coletadas de uma mesma altura, de plantas cultivadas sob iguais condições edafoclimáticas.

As diferenças apontadas anteriormente para as plantas deste estudo, embora cultivadas em áreas contíguas, são importantes porque segundo Evans (1999), a estrutura foliar atua sobre a atividade específica da Rubisco, devido às limitações internas de sua difusão, o que causa alterações na eficiência fotossintética. De acordo com Oguchi et al. (2003), menor incremento na espessura do mesofilo pode implicar que alguns cloroplastos se sobreponham no interior das células, pouco contribuindo para elevar as taxas fotossintéticas; deste modo, infere-se que dentre folhas do mesmo estrato, o aumento da espessura atue favoravelmente. Quanto a esta variável, foi verificado que alguns clones IAC apresentaram tanto indicativos de melhor desempenho que a testemunha, especialmente IAC 300, quanto de menor desempenho, especialmente IAC 40.

Contudo, embora a menor espessura seja considerada uma característica adaptativa de folhas de sombra, a partição entre os parênquimas clorofilianos, segundo o modelo proposto por Evans (1999), apesar de constituir um aspecto anatômico relevante, possui pouca influência

Tabela 1. Valores médios (em mg. $\mathrm{g}^{-1}$ de peso de matéria fresca) dos teores de clorofila a (chla), clorofila b (chlb), clorofilas totais (chla+b), carotenóides totais (car); razão (chla/chlb) e (chla+b/car), em folhas sombreadas de sete clones adultos de seringueira

\begin{tabular}{lcccccc}
\hline Clone & Chla & Chlb & Chla+b & Chla/Chlb & Car & (Chla+Chlb)/Car \\
\hline RRIM 600 & $2,20 \mathrm{bc}$ & $0,44 \mathrm{c}$ & $2,65 \mathrm{c}$ & $4,90 \mathrm{a}$ & $0,85 \mathrm{~b}$ & $3,09 \mathrm{ab}$ \\
IAC 40 & $2,64 \mathrm{ab}$ & $0,57 \mathrm{bc}$ & $3,21 \mathrm{bc}$ & $4,72 \mathrm{ab}$ & $1,15 \mathrm{ab}$ & $2,88 \mathrm{bc}$ \\
IAC 56 & $3,22 \mathrm{a}$ & $0,93 \mathrm{a}$ & $4,15 \mathrm{a}$ & $3,47 \mathrm{~b}$ & $1,21 \mathrm{a}$ & $3,29 \mathrm{a}$ \\
IAC 300 & $1,59 \mathrm{c}$ & $0,45 \mathrm{c}$ & $2,44 \mathrm{c}$ & $3,57 \mathrm{ab}$ & $0,87 \mathrm{~b}$ & $2,80 \mathrm{c}$ \\
IAC 301 & $2,84 \mathrm{ab}$ & $0,75 \mathrm{ab}$ & $3,59 \mathrm{ab}$ & $3,87 \mathrm{ab}$ & $1,19 \mathrm{a}$ & $3,04 \mathrm{abc}$ \\
IAC 302 & $2,42 \mathrm{~b}$ & $0,56 \mathrm{c}$ & $2,98 \mathrm{bc}$ & $4,41 \mathrm{ab}$ & $1,01 \mathrm{ab}$ & $2,95 \mathrm{bc}$ \\
IAC 303 & $2,43 \mathrm{~b}$ & $0,53 \mathrm{c}$ & $2,96 \mathrm{bc}$ & $4,58 \mathrm{ab}$ & $0,99 \mathrm{ab}$ & $3,00 \mathrm{bc}$ \\
Média geral & 2,48 & 0,61 & 3,14 & 4,22 & 1,04 & 1,80 \\
F & $7,56 *$ & $12,57^{*}$ & $9,11^{*}$ & $3,31^{*}$ & $4,72^{*}$ & $6,14^{*}$ \\
\hline
\end{tabular}

* Médias estatisticamente diferentes (5\% de probabilidade) são seguidas por letras distintas.

Tabela 2. Valores médios (em $\mu \mathrm{m}$ ) da espessura foliar total (EFT); parênquima paliçádico superior (PPS), parênquima paliçádico inferior (PPI), parênquima paliçádico total (PPT) e parênquima lacunoso (PL), em $\mu \mathrm{m}$, e proporção relativa entre os parênquimas clorofilianos (PPT/PL) em folhas sombreadas de sete clones adultos de seringueira

\begin{tabular}{|c|c|c|c|c|c|c|}
\hline Clone & EFT & PPS & PPI & PPT & PL & PPT/PL \\
\hline RRIM 600 & $121,58 b$ & $44,03 d$ & $16,57 \mathrm{ab}$ & $60,79 b$ & $36,00 \mathrm{bc}$ & $1,77 \mathrm{bc}$ \\
\hline IAC 40 & $106,27 d$ & $47,0 \mathrm{bc}$ & $15,67 b$ & $62,62 \mathrm{ab}$ & $27,48 \mathrm{~d}$ & $2,38 a$ \\
\hline IAC 56 & $111,26 \mathrm{~cd}$ & $39,85 \mathrm{e}$ & $13,48 c$ & 53,12 c & 33,49 c & $1,64 \mathrm{~cd}$ \\
\hline IAC 300 & $129,80 a$ & $50,34 a$ & 16,79ab & $64,55 \mathrm{ab}$ & 42,29 a & $1,53 \mathrm{~d}$ \\
\hline IAC 301 & $125,95 a b$ & 49,5ab & $17,10 \mathrm{a}$ & $66,55 \mathrm{a}$ & $40,05 \mathrm{ab}$ & 1,76 bc \\
\hline IAC 302 & $118,62 b c$ & $45,42 \mathrm{~cd}$ & $15,99 a b$ & $61,21 \mathrm{~b}$ & $35,96 \mathrm{c}$ & 1,76 bc \\
\hline IAC 303 & 123,87ab & $50,67 a$ & $16,20 \mathrm{ab}$ & 66,25 a & 36,67 bc & $1,90 \mathrm{~b}$ \\
\hline Média geral & 119,62 & 46,69 & 15,97 & 62,16 & 35,99 & 1,82 \\
\hline $\mathrm{F}$ & $19,282 *$ & $44,67 *$ & $14,70^{*}$ & $16,27 *$ & $20,28 *$ & $25,94 *$ \\
\hline
\end{tabular}

* Médias estatisticamente diferentes (5\% de probabilidade) são seguidas por letras distintas

Rev. Ceres, Viçosa, v. 58, n.1, p. 29-34, jan/fev, 2011 
funcional. De acordo com este autor, o parênquima paliçádico (PP), por estar mais próximo da superfície, recebe a luz e facilita a sua penetração em camadas mais profundas, enquanto que o parênquima lacunoso (PL) promove o espalhamento para facilitar a sua absorção, minimizando o efeito da proporção PL/PP e das suas diferenças significativas aqui observadas.

Os resultados referentes às variáveis biométricas são apresentados na Tabela 3. A média geral da área foliar foi de $219,17 \mathrm{~cm}^{2}$, sendo que todos os clones apresentaram valores estatisticamente similares aos da testemunha; no entanto, entre os clones IAC, houve uma tendência de maior área foliar para IAC 56 e IAC 303, e de menor área para IAC 300. O peso médio da massa seca foliar foi de 1,12 g, e, neste caso, alguns clones IAC apresentaram valores estatisticamente inferiores aos da testemunha, especialmente IAC 300. A área foliar específica, ou seja, a razão entre a área foliar e o peso da massa seca, apresentou um valor médio de 198,08 $\mathrm{cm}^{2} \mathrm{~g}^{-1}$ e, neste caso, também houve diferenças estatísticas entre a testemunha e os clones IAC, e dentro dos clones IAC.

As plantas adaptam-se à sombra expandindo a lâmina foliar, o que maximiza a interceptação da claridade e o uso da luz mais eficientemente, levando ao aumento do ganho de carbono sob irradiações solares baixas (Scalon et al., 2001; Senevirathna et al., 2003; Lima Junior et al., 2005). Neste caso, numa primeira análise, pode-se supor que os clones IAC 56 e 303 apresentariam melhores respostas que os demais IAC.

Contudo, as trocas gasosas também são influenciadas pela AFE, que atua sobre a condutância e competição pelo $\mathrm{CO}_{2}$ nos sítios de carboxilação (Mediavilla et al., 2001). O aumento do sombreamento leva a um progressivo aumento da AFE, sendo que os valores chegam a dobrar quando se comparam folhas de pleno sol ou aquelas sob 77\% de sombreamento (Senevirathna et al.,2003). Assim, sob iguais condições ambientais, folhas com maior AFE teriam investimento maior na maquinaria fotossintética do que em tecidos de sustentação (Lima Junior et al., 2005).
Com relação a este parâmetro, IAC 56 apresentou o maior valor, tanto com relação à testemunha quanto dentre os clones IAC.

Deste modo, sob condições de sombra, uma folha hipoteticamente ideal possuiria uma grande área foliar, com espessura suficiente para uma boa distribuição dos cloroplastos, alto teor de pigmentos fotossintéticos (sobretudo clorofila $b$ e carotenóides) e uma área foliar específica alta. Comparando os clones IAC com a testemunha, os teores de clorofila $b$, carotenóides e área foliar foram iguais ou superiores; quanto à AFE, somente a do IAC 56 foi maior, e quanto à espessura foliar, foram observados valores estatisticamente iguais, superiores e até mesmo inferiores.

Embora não tenha sido o objetivo principal deste estudo, quando os dados relativos à produtividade média destas plantas são comparados com os dados de anatomia foliar, pelo menos uma correlação foi fortemente sugerida. Segundo os dados divulgados por Gonçalves et al. (2006), após seis anos de sangria, as porcentagens de produção com relação à testemunha RRIM 600 (100\%) foram de $155 \%$ para IAC 40; 113\% para IAC 56; $128 \%$ para IAC 300; 122\% para IAC 301; 114\% para IAC 302 e 107\% para IAC 303. Quando todas as variáveis foliares aqui analisadas são consideradas, verifica-se que entre IAC 303 e a testemunha não foram verificadas diferenças estatisticamente significativas, e a variação percentual da produtividade foi a menor observada (na ordem de 7\%).

No entanto, embora para IAC 302 e a testemunha também tenha sido verificada grande similaridade quanto às características foliares estudadas, o percentual de produção com relação à testemunha teve maior amplitude (14\%), a qual foi bastante próxima à verificada para IAC 56 (13\%), que apresentou diferenças significativas quanto à testemunha em muitas das variáveis avaliadas. Uma vez que a investigação sobre os fatores diretamente ligados à produção ainda requer muitas respostas, diante da possível relação observada, sugere-se que estas análises foliares sejam estendidas para um maior número de clones.

Tabela 3. Valores médios da área foliar $\left(\mathrm{cm}^{2}\right)$, peso da massa seca foliar (g) e área foliar específica (AFE, $\left.\mathrm{cm}^{2} \mathrm{~g}^{-1}\right)$ em folhas sombreadas de sete clones adultos de seringueira

\begin{tabular}{lccc}
\hline Clone & Área foliar & Peso Massa Seca Foliar & AFE \\
\hline RRIM 600 & $230,71 \mathrm{ab}$ & $1,20 \mathrm{ab}$ & $191,17 \mathrm{bc}$ \\
IAC 40 & $206,31 \mathrm{ab}$ & $1,16 \mathrm{abc}$ & $178,59 \mathrm{c}$ \\
IAC 56 & $278,76 \mathrm{a}$ & $1,25 \mathrm{ab}$ & $232,38 \mathrm{a}$ \\
IAC 300 & $151,00 \mathrm{~b}$ & $0,74 \mathrm{c}$ & $198,22 \mathrm{bc}$ \\
IAC 301 & $189,98 \mathrm{ab}$ & $0,95 \mathrm{bc}$ & $198,94 \mathrm{bc}$ \\
IAC 302 & $204,39 \mathrm{ab}$ & $1,04 \mathrm{abc}$ & $202,07 \mathrm{~b}$ \\
IAC 303 & $273,05 \mathrm{a}$ & $1,48 \mathrm{a}$ & $185,24 \mathrm{bc}$ \\
Média geral & 219,17 & 1,12 & 198,08 \\
F & $5,46^{*}$ & $6,27^{*}$ & $16,03^{*}$ \\
\hline
\end{tabular}

* Médias estatisticamente diferentes (5\% de probabilidade) são seguidas por letras distintas. 


\section{CONCLUSÃO}

No conjunto de variáveis analisadas, as folhas sombreadas dos clones IAC 302 e IAC 303 apresentaram similaridade estatística às da testemunha RRIM 600 e, para IAC 303, uma possível relação com a produtividade foi sugerida.

\section{REFERÊNCIAS}

Arnon DI (1949) Cooper enzymes in isolated chloroplasts: polyphenoloxidases in Beta vulgaris. Plant Physiology, 24: 115.

Conforto EC (1995) Estado hídrico e alguns parâmetros fenológicos, anatômicos, biométricos e produtivos de três cultivares de seringueira (Hevea spp) em Piracicaba, SP. Tese de Doutorado. Universidade Estadual Paulista, Instituto de Biociências, Rio Claro, 192 p.

Engel VL \& Poggiani F (1991) Estudo da concentração de clorofila nas folhas e seu espectro de absorção de luz em função do sombreamento em mudas de quatro espécies florestais nativas. Revista Brasileira de Fisiologia Vegetal, 3: 39-45.

Evans JR (1999) Leaf anatomy enables more equal access to light and $\mathrm{CO}_{2}$ between chloroplasts. New Phytology, 143: 93-104.

Gameiro AH \& Perozzi MB (2008) Perspectivas para o Brasil no cenário internacional da borracha natural - parte I. Disponível em: http://www.apabor.org.br/sitio/indez.htm. Acesso em: 10 junho 2008.

Gomez JB \& Hamzah SB (1980) Variations in leaf morphology and anatomy between cultivars of Hevea. Journal of Rubber Research Institute of Malaysia, 28: 157-172.

Gonçalves PS, Aguiar ATE \& Gouvea LRL (2006) Expressão fenotípica de clones de seringueira na região noroeste do Estado de São Paulo. Bragantia, 65: 389-398.

Hendry GAF \& Price AH (1993) Stress indicators: cholorophylls and carotenoids. In: Hendry GAF \& Grime JP (Eds) Methods in comparative plant ecology. London, Chapman Hall, p. 148152.

Hiscox JD \& Israelstam GF (1979) A method for the extraction of chlorophyll from leaf tissue without maceration. Canadian Journal of Botany, 57: 1332-1334.

Johansen DA (1940) Plant Microtechnique. McGraw-Hill, New York, 523p.

Lemos Filho JP, Nova NAV \& Pinto HS (1993) Base temperature and heat units for leaf flushing emission and growth of Hevea brasiliensis Müell. Arg. International Journal of Biometerology, 37: 65-67.

Lim TM \& Narayanan R (1972) Estimation of the area of rubber leaves (Hevea brasiliensis Müell. Arg.) using two leaflet parameters. Experimental Agriculture, 8: 311-314.

Lichtenhaler HK, Marek M, Kalina J \& Urban O (2007) Differences in pigments composition, photosynthetic rates and chlorophyll fluorescence images of sun and shade leaves of four tree species. Plant Physiology and Biochemistry, 45: 577-588.

Lima Junior EC, Alvarenga AA, Castro EM, Vieira CV \& Oliveira HM (2005) Trocas gasosas, características das folhas e crescimento de plantas jovens de Cupania vernalis Camb. submetidas a diferentes níveis de sombreamento. Ciência Rural, 35: 10921097.

Martins MBG \& Zieri R (2003) Leaf anatomy of rubber-tree clones. Scientia Agricola, 60: 709-713.
Mediavilla S, Escudero A \& Heilmeier H (2001) Internal leaf anatomy and photosynthetic resource-use efficiency: interspecific and intraspecific comparisons. Tree Physiology, 21: 251-259.

Medri ME (1977) Alguns aspectos da anatomia ecológica de folha de Hevea brasiliensis Müell. Arg. Dissertação de Mestrado. Instituto Nacional de Pesquisa da Amazônia, Manaus, 107 p.

Medri ME (1980) Anatomia comparada e correlações anatomofisiológicas de seis cultivares de Hevea spp. Tese de Doutorado. Manaus, 1980. 422 p.

Medri ME \& Lleras E (1981) Comparação anatômica entre folhas de um cultivar diplóide (IAN 873) e dois cultivares poliplóides (IAC 207, 222) de Hevea brasiliensis Müell. Arg. Acta Amazonica, 11: 35-47.

Medri ME \& Lleras E (1983) Quantificação e uso de caracteres anatômicos e fisiológicos de folhas de seringueira na determinação da eficiência hídrica em cultivares de Hevea spp. Acta Amazonica, 13: 261-288.

Miguel AA, Oliveira LEM, Cairo PAR \& Oliveira DM (2007) Photosynthetic behaviour during the leaf ontogeny of rubber tree clones [Hevea brasiliensis (Wild. Ex. Adr. de Jus) Müell. Arg.], in Lavras, MG. Ciência Agrotecnológica, 31: 91-97.

Nakazono EM, Costa MC, Futatsugi K \& Paulilo MTS (2001) Crescimento inicial de Euterpe edulis Mart. em diferentes regimes de luz. Revista Brasileira de Botânica, 24: 173-179.

Nataraja KN \& Jacob J (1999) Clonal differences in photosynthesis in Hevea brasiliensis Müell. Arg. Photosynthetica, 36: 89-98.

Oguchi R, Hikosaka K, Hiura T \& Hirose T (2003) Leaf anatomy and light acclimation in woody seedlings after gap formation in a cool-temperature deciduous forest. Oecologia, 149: 571-582.

Press M (1999) Research review: The functional significance of leaf structure: a search for generalizations. New Phytology, 143: 213-219

Roeser KR (1972) Die Nadel der Schwarzkiefer - Massenproduckt und Kunstwerk der Natur. Mikrokosmos, 61: 33-36.

Scalon SPQ; Scalon Filho H, Rigoni MMR \& Veraldo F (2001) Germinação e crescimento de mudas de pitangueira (Eugenia uniflora L.) sob condições de sombreamento. Revista Brasileira de Fruticultura, 23: 652-655.

Senevirathna AMWK, Stirling CM \& Rodrigo VHL (2003) Growth, photosynthetic performance and shade adaptation of rubber (Hevea brasiliensis) grown in natural shade. Tree Physiology, 23: $705-712$.

Terashima I, Hanba YT, Tazoe Y, Vyas P, Yano S. (2006) Irradiance and phenotype: comparative eco-development of sun and shade leaves in relation to photosynthetic $\mathrm{CO}_{2}$ diffusion. Journal of Experimental Botany, 57: 343-354.

UFSCar (2008) Universidade Federal de São Carlos, Departamento de Tecnologia Agroindustrial e Socioeconomia Rural. Acessado em: 14 março 2008.

Yano S \& Terashima I (2001) Separate localization of light signal perception for sun or shade type chloroplast and palisade tissue differentiation in Chenopodium album. Plant and Cell Physiology, 42: 103-1310.

Zar JH (1999) Biostatistical Analysis. New Jersey, Prentice. 663p.

Rev. Ceres, Viçosa, v. 58, n.1, p. 29-34, jan/fev, 2011 